\title{
Phenylketonuria screening and management in southeastern Europe - survey results from 11 countries
}

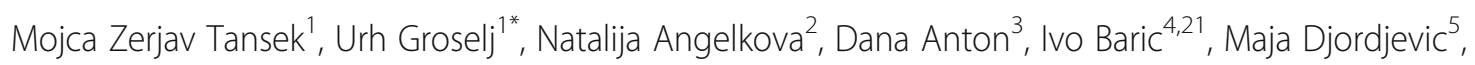
Lindita Grimci ${ }^{6}$, Maria Ivanova ${ }^{7}$, Adil Kadam ${ }^{8}$, Vjosa Kotori ${ }^{9}$, Hajrija Maksic ${ }^{10}$, Oana Marginean ${ }^{11}$, Otilia Margineanu ${ }^{12}$, Olivera Miljanovic ${ }^{15}$, Florentina Moldovanu ${ }^{13}$, Mariana Muresan ${ }^{14}$, Michaela Nanu $^{13}$, Mira Samardzic ${ }^{15}$, Vladimir Sarnavka ${ }^{4}$, Aleksei Savov ${ }^{7}$, Maja Stojiljkovic ${ }^{16}$, Biljana Suzic $^{17}$, Radka Tincheva $^{8}$, Husref Tahirovic $^{18}$, Alma Toromanovic ${ }^{19}$, Natalia Usurelu ${ }^{20}$ and Tadej Battelino ${ }^{1,22^{*}}$

\begin{abstract}
Background: We aimed to assess the current state of PKU screening and management in the region of southeastern Europe.

Methods: A survey was performed involving all identified professionals responsible for the PKU management in the 11 countries from South-Eastern region of Europe (Albania, Bulgaria, Bosnia and Herzegovina, Croatia, Kosovo, Macedonia, Moldova, Montenegro, Romania, Serbia, Slovenia). The questionnaire was designed to assess the characteristics regarding PKU management in three main areas: nation-wide characteristics, PKU screening, and characteristics of the PKU management in the responding centre. It consisted of 56 questions. The distribution and collection of the questionnaires (via e-mail) was taking place from December 2013 to March 2014.
\end{abstract}

Results: Responses from participants from 11 countries were included; the countries cumulative population is approx. 52.5 mio. PKU screening was not yet introduced in 4 of 11 countries. Reported PKU incidences ranged from 1/7325 to 1/39338 (and were not known for 5 countries). National PKU guidelines existed in 5 of 11 countries and 7 of 11 countries had PKU registry (registries included 40 to 194 patients). The number of PKU centers in each country varied from 1 to 6 . Routine genetic diagnostics was reported in 4 of 11 countries. Most commonly used laboratory method to assess phenylalanine levels was fluorometric. Tetrahydrobiopterine was used in only 2 of 11 countries. Most frequently, pediatricians were caring for the patients. Dietitian was a member of PKU team in only 4 of 11 countries, while regular psychological assessments were performed in 6 of 11 countries. Patient's PKU society existed in 7 of 11 countries.

Conclusions: The region of southeastern Europe was facing certain important challenges of PKU screening and management. Neonatal PKU screening should be introduced throughout the region. Furthermore, PKU management was falling behind internationally established standards-of-care in many aspects.

Keywords: Phenylketonuria, PKU, Hyperphenylalaninemia, Screening, Management, Survey, Southeastern Europe, Recommendations, Standards of care

\footnotetext{
* Correspondence: urh.groselj@kclj.si; tadej.battelino@mf.uni-lj.si

'University Children's Hospital Ljubljana, UMC Ljubljana, Ljubljana, Slovenia.

${ }^{22}$ Department of Pediatrics, Faculty of Medicine, University of Ljubljana,

Ljubljana, Slovenia.

Full list of author information is available at the end of the article
} 


\section{Background}

Phenylketonuria (PKU; MIM 261600), an autosomal recessive disease, is the most common inborn error of amino acid metabolism in Caucasians, where 1 in 10,000 individuals is affected, but the incidences vary substantially among different populations $[1,2]$. PKU is caused by the deficiency of hepatic phenylalanine hydroxylase (PAH; EC 1.14.16.1), which catalyzes the hydroxylation of phenylalanine (Phe) to tyrosine (Tyr). The PAH deficiency results in an accumulation of Phe, acting neurotoxically $[1,3]$ The dietary therapy based on a restricted Phe intake prevents the neurological damage in most cases if started soon enough after birth and if guided with frequent monitoring of Phe concentrations [4]. Fifty years ago, Guthrie's landmark discovery enabled successful implementation of first newborn screening programs for PKU, which have been implemented throughout the developed world [5].

All current guidelines, recommendations and reviews on PKU screening and management agree on some basic facts and requirements. Most notably that PKU screening is a prerequisite for an early implementation of the Pherestricted diet, which is necessary to prevent the severe neurological impairment, observed in untreated PKU patients $[6,7]$. Furthermore, dietary PKU treatment with regular monitoring of blood Phe levels is mandatory at least throughout childhood, adolescence, and in pregnant women, but ideally throughout the life etc. [8]. Very recently, the European Society for Phenylketonuria and Allied Disorders (E.S.PKU) proposed a need for recommendations for a minimum standard of care for PKU, guaranteeing equal access to screening, treatment and monitoring throughout Europe [9]. Nevertheless, PKU screening and management practices vary widely throughout the individual PKU centers, countries and regions, and large parts of the world might fall behind even the basic standards. Relatively few previous international studies on PKU management have been performed, mostly focusing on the more developed parts of Europe, while large parts of eastern and southeastern Europe could not be assessed in previous European surveys [10-15].

Since very scarce data exist on PKU management in region of southeastern Europe, the aim of our study was to assess the current state of PKU screening and management in the region of southeastern Europe (i.e. Balkan Peninsula countries).

\section{Methods}

\section{Study design and questionnaire}

Survey was performed involving all identified professionals responsible for the PKU management in the countries from South-Eastern region of Europe (Albania, Bulgaria, Bosnia and Herzegovina, Croatia, Kosovo, Macedonia, Moldova, Montenegro, Romania, Serbia,
Slovenia). From one to five participants from each participating country were included in survey, as suggested by the responsible person from each country. The questionnaire was designed to assess the characteristics regarding PKU management in three main areas: nationwide characteristics, PKU screening, and characteristics of the PKU management in the responding centre. It consisted of altogether 56 questions (13 of them were on general aspects of neonatal screening, which were analyzed separately). The full questionnaire is provided as an online Additional file 1.

The first part of the questionnaire included the questions on PKU screening characteristics (year of introduction; number and proportion of newborn screened; age when screened; PKU/HPA incidences; laboratory screening method; Phe cut-off). The second part included questions on nation-wide characteristics of PKU management (PKU guidelines; number and type of PKU centers; PKU registry; definition of metabolic phenotypes; on who cares for PKU patients; availability of medical food, low protein food and tetrahydrobiopterine (BH4), money reimbursements/money support; existence of patient's society, membership in E.S.PKU). The third part included questions on specific characteristics of responding PKU center (number of patients to follow-up according to age, diet, metabolic phenotypes; number of lost to follow-up, genetic analyses; laboratory methods used; BH4 use; composition of PKU team, dietary plans preparation; psychological assessments; care for adults; care for pregnant women).

The distribution and collection of the questionnaires was made by e-mail and was taking place from December 2013 to March 2014.

\section{Data analysis}

All responses were compiled in a spreadsheet, and most of the open questions grouped or categorized and tabulated. Descriptive analyses were performed in the form of sums (reported as percent of total responses) and medians. From each country (with exception of Bosnia and Herzegovina where three different responses for Sarajevo Canton, for Republic of Srpska and for Federation of Bosnia and Herzegovina without Sarajevo were obtained, reflecting the functioning of their healthcare system as three effectively separate subsystems, including the newborn screening) only single completed questionnaires were obtained, filled and e-mailed by the responsive participant from each country, who in some instances completed the questionnaire with help by other professionals from the country, which were also listed as coauthors. Answers to some of the questions could not be included as the variations between responses were too large or too few responses were received and thus no meaningful grouping and interpretation of results could be made. 
The main focus of data interpretation was to assess the current status of PKU management in the region of South-Eastern Europe, especially to elucidate the common difficulties in PKU management in the region.

\section{Results}

Responses from participants from all 11 countries were included; the countries cumulative population was approx. 52.5 mio; Montenegro had the smallest population (0.63 mio.) and Romania the largest (18.91 mio.). Bosnia and Herzegovina was effectively divided in 3 separately functioning healthcare systems, including the newborn screening systems, despite a small population of 3.8 mio. The GDP per capita ranged from around 4000 (Moldova) to 28,000 USD (Slovenia). The number of newborns in 2012 ranged from 8156 (Montenegro) to 195,000 (Romania) (Table 1).

PKU newborn screening was not introduced in 4 of 11 countries (Albania, Kosovo, Macedonia, Montenegro). In two countries (Bulgaria, Romania) where the newborn screening was introduced, over $10 \%$ of newborns were not screened. Number of newborn screening centers ranged from none to five (Romania). Most commonly used screening method was fluorometric, while Guthrie's test was still used in Croatia and enzymatic/colorimetric method in Serbia. The Phe cut-off values ranged from 2 to $4 \mathrm{mg} / \mathrm{dl}$. Reported estimates of PKU incidences ranged from $1 / 7325$ to $1 / 39,338$ (and were not known for 5 countries). Six of 11 countries had established national PKU registries and one country had registry in preparation. National PKU registries included 40 to 194

Table 1 Demographics and general phenylketonuria screening and management characteristics

\begin{tabular}{|c|c|c|c|c|c|c|c|c|c|c|}
\hline & $\begin{array}{l}\text { Total } \\
\text { pop. } \\
\text { (millions) }\end{array}$ & $\begin{array}{l}\text { GDP per } \\
\text { cap. in } 2012 \\
\text { (USD) }\end{array}$ & $\begin{array}{l}\text { First year of } \\
\text { PKU } \\
\text { screening }\end{array}$ & $\begin{array}{l}\text { Screened / } \\
\text { all nbs in } \\
2012\end{array}$ & $\begin{array}{l}\text { Classic } \\
\text { PKU } \\
\text { incidence }\end{array}$ & $\begin{array}{l}\text { Phe screening } \\
\text { cut-off } \\
(\mathrm{mg} / \mathrm{dl})\end{array}$ & $\begin{array}{l}\text { Age when } \\
\text { screened } \\
\text { (h) }\end{array}$ & $\begin{array}{l}\text { National } \\
\text { PKU } \\
\text { registry }\end{array}$ & $\begin{array}{l}\text { No. patients } \\
\text { in the PKU } \\
\text { registry }\end{array}$ & $\begin{array}{l}\text { Children/ } \\
\text { Adults } \\
\text { care }\end{array}$ \\
\hline Albania & 2.83 & 9403 & $\mathrm{NI}$ & $-/ 35,295$ & Unknown & - & - & No & - & $\mathrm{Nd}$ \\
\hline $\begin{array}{l}\text { Bosnia - FBH } \\
\text { (without Sarajevo } \\
\text { Canton) }\end{array}$ & 2.07 & 9392 & $\begin{array}{l}2001(T z) \\
2005\end{array}$ & $\begin{array}{l}16,915^{a} / \\
16,790\end{array}$ & $\begin{array}{l}1 / 29,998 \\
\text { (est.) }\end{array}$ & 4 & $48-120$ & No & - & Ped/Ped \\
\hline $\begin{array}{l}\text { Bosnia - Rep. } \\
\text { Srpska }\end{array}$ & 1.33 & 9392 & $\begin{array}{l}1986(\mathrm{BL}) \\
2007\end{array}$ & $9907 / 9978$ & $\begin{array}{l}1 / 34,817 \\
\text { (est.) }\end{array}$ & $2.1-3$ & $48-72$ & In prep. & - & Ped/Ped \\
\hline $\begin{array}{l}\text { Bosnia - Sarajevo } \\
\text { Canton }\end{array}$ & 0.44 & 9392 & 2006 & $5152 / 5167$ & Unknown & 2.1 & $\begin{array}{l}24 \\
\text { (96 if CS) }\end{array}$ & No & - & Ped/Ped \\
\hline Bulgaria & 7.36 & 16,041 & 1979 & $\begin{array}{l}62,496 / \\
69,121\end{array}$ & $\begin{array}{l}1 / 28,370 \\
b\end{array}$ & 3.3 & 72 & Yes & $74^{c}$ & $\mathrm{Ped} / \mathrm{Int}$ \\
\hline Croatia & 4.28 & 20,961 & $\begin{array}{l}1978(\mathrm{Zg}) \\
1986\end{array}$ & $\begin{array}{l}41,606 / \\
41,700\end{array}$ & $\underset{d}{1 / 12,000}$ & 4 & 72 & Yes & 194 & Ped/Ped \\
\hline Kosovo & 1.74 & 8436 & $\mathrm{NI}$ & $-/ 34,262$ & Unknown & - & - & No & - & $\mathrm{Nd}$ \\
\hline Macedonia & 2.06 & 11,834 & $\mathrm{NI}$ & $-/ 23752$ & Unknown & - & - & No & - & Ped/Int \\
\hline Moldova & 3.50 & 4219 & 1989 & $\begin{array}{l}36,654 / \\
39,641\end{array}$ & $1 / 7325^{e}$ & 3 & $>48$ & Yes & 101 & Gen/Gen \\
\hline Montenegro & 0.63 & 14,358 & $\mathrm{NI}$ & $-/ 8156$ & Unknown & - & - & No & - & $\mathrm{Nd}$ \\
\hline Romania & 18.91 & 18,063 & 2011 & $\begin{array}{l}141,204 / \\
195,000\end{array}$ & $\begin{array}{l}1 / 10,000 \\
\text { (est.) }\end{array}$ & 3 & $48-72$ & Yes & $40^{c}$ & $\mathrm{Ped} / \mathrm{Int}$ \\
\hline $\begin{array}{l}\text { Serbia } \\
\text { (without Vojvodina) }\end{array}$ & 7.18 & 11,801 & 1983 & $\begin{array}{l}52,094 / \\
49,325^{f}\end{array}$ & $1 / 39,338^{g}$ & 2 & $48-72$ & Yes & 63 & Ped/Ped \\
\hline Slovenia & 2.05 & 28,476 & 1979 & $\begin{array}{l}21,888 / \\
21,938\end{array}$ & $1 / 10,000^{h}$ & $2.1-3$ & $48-72$ & Yes & 145 & Ped/Ped \\
\hline
\end{tabular}

BL only in region Banja Luka; cap capita; CS cesarean section; est. estimation; FBH Federation of Bosnia and Herzegovina; GDP gross domestic product; Gen geneticists; $h$ hours; Int internists; $n b$ s newborns; $N d$ no data available; NI not introduced yet; Ped pediatricians; Phe phenylalanine; PKU phenylketonuria; prep. preparation; Rep. Republic; Tz only in Tuzla Canton; $\mathrm{Zg}$ only in city Zagreb

${ }^{a}$ Number includes some newborns from Brcko District

${ }^{b}$ Kremensky et al, please see ref. [17]

${ }^{\mathrm{C} B u l g a r i a n}$ national PKU registry was established in the year 2000; Romanian national PKU registry was established in the year 2011. Both are including only patients diagnosed afterwards

${ }^{\mathrm{d}}$ Karacic et al, please see ref. [23]

e Hyperphenylalaninemias cumulatively; Published in: Boiciuc K, Usurelu N, Stratila M, Sacara V: Fenilcetonuria in Rešpublica Moldova - diagnosticul prin screening neonatal si analiza molecular genetic. In Patologa malformativa neonatal. Edited by Stamatin M, Stratulat P. Zilele Neonatologiei Moldave,

Technopress; 2013:146-153

${ }^{\mathrm{f}}$ Number of screened newborns includes some screening cards from Vojvodina and Montenegro

${ }^{9}$ Stojiljkovic et al, please see ref. [18]

${ }^{\mathrm{h}}$ Groselj et al, please see ref. [22] 
patients. Most frequently, pediatricians were caring for the children and adult patients (Bosnia, Croatia, Serbia, Slovenia), internists were following the adult patients in Bulgaria, Macedonia and Romania but geneticists were responsible for all PKU patients in Moldova (Table 1).

The number of PKU centers in each country varied from one to six. Bulgaria and Romania had one adult only PKU center each, while all the other countries had combined pediatric/adult or pediatric only PKU centers.

The responding PKU centers were following up to 176 PKU patients on dietary treatment. Only three centers were also following patients with $\mathrm{BH} 4$ deficiency. Routine genetic diagnostics was reported by PKU centers in four of 11 countries. Most commonly used laboratory method to monitor Phe levels was fluorometric. In Kosovo, Macedonia and Albania Phe-free amino acids supplements and low protein food were not reimbursed. The patients got no financial support for low protein food in Bulgaria and Moldova. BH4 was routinely used in only 2 of 11 countries. Dietitian was a member of PKU team in only 4 of 11 countries. Psychological assessments were regularly performed in 6 of 11 countries with very diverse developmental tests and without involvement of a neuropsychologist. The management of maternal PKU was reported in 5 countries (Table 2).

National PKU guidelines existed in five of 11 countries (Bulgaria, Croatia, Moldova, Serbia, Slovenia) based on several different published recommendations. Some countries are following U.K. and U.S.A. guidelines (Bosnia, Bulgaria, Macedonia) or USSR recommendations (Moldova). Seven of 11 countries had patients/parents PKU society, while only in six of 11 countries reported to be E.S.PKU members.

\section{Discussion}

This was the first study to assess the PKU screening and management characteristics in the region of southeastern Europe, involving 11 countries from the region with a cumulative population of approx. 52.5 mio. The included populations are thought to be ethnically and genetically very heterogeneous, which was reflected also by the variations of PKU incidences [15-17]. Even within the same country large differences are reported; for instance, in Croatia, the incidence of PKU in the region "Hrvatsko Zagorje" is about $1 / 3.500$, while in the region of "Dalmatia" only $1 / 15.500$ [15]. The incidence of

Table 2 Phenylketonuria - single center characteristics and experiences

\begin{tabular}{|c|c|c|c|c|c|c|c|c|c|c|}
\hline & $\begin{array}{l}\text { No. of } \\
\text { patient } \\
\text { on diet }\end{array}$ & $\begin{array}{l}\text { Lost to follow-up } \\
\left(<1 y_{i}<18 y_{i}>18 y\right)\end{array}$ & $\begin{array}{l}\text { Diet in CPKU } \\
\text { and other HPA }\end{array}$ & $\begin{array}{l}\text { No. } \\
\text { BH4 def. }\end{array}$ & $\begin{array}{l}\text { Genotype } \\
\text { analyses }\end{array}$ & $\begin{array}{l}\text { Phe lab. } \\
\text { methods }\end{array}$ & $\begin{array}{l}\mathrm{BH} 4 \\
\text { therapy use }\end{array}$ & $\begin{array}{l}\text { PKU team } \\
\text { members }^{a}\end{array}$ & $\begin{array}{l}\text { Psychological } \\
\text { assessments }^{b}\end{array}$ & $\begin{array}{l}\text { Pregnant } \\
\text { PKU } \\
\text { women? } \\
\text { (No.) }\end{array}$ \\
\hline Albania & $1^{\mathrm{C}}$ & - & - & 0 & No & - & No & 0 & - & No \\
\hline $\begin{array}{l}\text { Bosnia - FBH } \\
\text { (without } \\
\text { Sarajevo } \\
\text { Canton) }\end{array}$ & 8 & 0; 30 \%; 50 \% (est.) & $6 ; 2$ & 0 & No & $\mathrm{F}$ & No & 0 & Not regular & No \\
\hline $\begin{array}{l}\text { Bosnia - Rep. } \\
\text { Srpska }\end{array}$ & 10 & $0 ; 0 ; 0$ & $5 ; 5$ & 0 & No & $\mathrm{F}$ & No & $0 ; 1 ; 3$ & $\begin{array}{l}\text { Every 6-12 } \\
\text { mo. }\end{array}$ & No \\
\hline $\begin{array}{l}\text { Bosnia - } \\
\text { Sarajevo }\end{array}$ & 2 & $\mathrm{Nd}$ & $2 ; 0$ & 0 & No & $\mathrm{F}$ & No & $0 ; 2$ & Every 12 mo. & No \\
\hline Bulgaria & 48 & $0 ; 0 ; 34$ & $47 ; 1$ & 0 & Yes & $\mathrm{F}$ & Yes & $0 ; 1 ; 2 ; 3$ & Every 12 mo. & In past (3) \\
\hline Croatia & 116 & 0; 20 \%; 61 \% (est.) & $81 ; 35$ & 0 & $\begin{array}{l}\text { Not } \\
\text { routinely }\end{array}$ & $C ; F ; G$ & No & $0 ; 1 ; 2 ; 3$ & $\begin{array}{l}\text { Every 12-48 } \\
\text { mo. }\end{array}$ & Yes (10) \\
\hline Kosovo & 0 & - & - & 0 & No & - & No & 0 & - & No \\
\hline Macedonia & 2 & $0 ; 1 ; 1$ & $2 ; 0$ & 0 & No & C & No & 0 & Every 12 mo. & No \\
\hline Moldova & 46 & $3 ; 7 ; 2$ & $31 ; 15$ & 0 & $Y_{e s}^{d}$ & $C ; F$ & No & $0 ; 2 ; 4$ & No & Yes (3) \\
\hline Montenegro & 0 & - & - & 0 & No & - & No & 0 & - & No \\
\hline Romania & 83 & $0 ; 0 ; \mathrm{Nd}$ & $63 ; 20$ & 5 & No & $\mathrm{F}$ & $\mathrm{No}^{\mathrm{e}}$ & $0 ; 1 ; 4$ & Every 6 mo. & No \\
\hline Serbia & 35 & $0 ; 3 ; 20$ & $18 ; 17$ & 1 & Yes & $C ; F$ & No & 0 & Every 6 mo. & Yes (2) \\
\hline Slovenia & 96 & $0 ; 0 ; 16$ & $70 ; 26$ & 2 & Yes & $C ; F ; T$ & Yes & $0 ; 3$ & Not regular & Yes (9) \\
\hline
\end{tabular}

BH4 tetrahydrobiopterine; C Chromatography; $C P K U$ classic phenylketonuria; def. deficiency; est. estimation; $F$ Fluorimetric method; $F B H$ Federation of Bosnia and Herzegovina; G Guthrie's test; HPA hyperphenylalaninemia; lab. laboratory; mo. months; Nd no data available; No. number; PKU phenylketonuria; Rep. Republic; $T$ Tandem mass spectrometry; $y$ year(s)

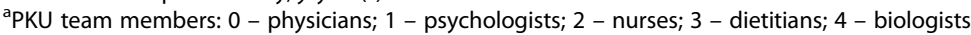

${ }^{b}$ Where performed, diverse developmental tests are used, without involvement of a neuropsychologist

cManaged in Turkey

${ }^{\mathrm{d}} 6$ most common $P A H$ alleles

ePlanned in near future and will be financed by the health insurance 
classical PKU is geographically scattered with significantly lower incidences in Serbia and Bulgaria [17, 18]. The reported PAH genotypes from the participating countries in different genetic studies are reflecting the heterogeneity of the populations but numerous historically documented migrations over the Balkan Peninsula were causing genetic similarity to other Caucasian populations [18-24]. The incidences are not known for 4 countries without newborn screening, while only estimations were possible for Bosnia and Romania. Taking the birth rates in the 4 countries without screening and the PKU incidence of 1/10,000 the expected number of the PKU patients would be 10 per year. The number seems low but the many lost screening years in this region in the last 40 years are suggesting a much higher number of missed opportunities for the diagnosis and treatment of PKU.

The most disturbing fact shown by our survey was that the PKU newborn screening was not introduced in 4 of 11 countries (Albania, Kosovo, Macedonia, Montenegro), while in two other countries (Bulgaria, Romania) where it was introduced, over $10 \%$ of newborns were not screened. Thus large parts of the region were falling behind the internationally established standards regarding the PKU screening $[6,8]$. In the countries with non existing newborn screening none or very few patients with PKU were diagnosed. In the countries with implemented newborn screening, the total numbers of diagnosed PKU patients born before the implementation of the newborn screening were available, but were very low as compared to the expected number of PKU patients based on the PKU incidences.

The possibility of treatment was very limited in Kosovo, Albania and Macedonia because amino acids supplements and low protein food were not reimbursed, while patients in Bulgaria and Moldova were reported not to get any additional financial support for the low protein diet. The nutritional recommendations and target Phe values in blood could be hardly met without sufficient amounts of low-Phe protein substitutes and low protein food. The unavailability and high prices of the medical food would be a further important limitation for PKU treatment in these countries in case of successful consolidation of newborn screening throughout the region.

Almost half of the countries reported the use of the national PKU guidelines. Fundamentally they are based on several published recommendations and the management of the patients is very similar [13, 25]. Surprisingly a dietitian was a part of PKU team in only 4 countries and in other PKU centers the dietary plan was a responsibility of the physicians. Previous European surveys show that basic PKU team consists of a physician and a dietitian [11-13], which was not shown to be a regular practice in the region of southeastern Europe. The quality of the dietary PKU management without a specialized dietitian may be insufficient. The multidisciplinary approach to include a dietitian is consistent with the requirements for minimum standards of care for PKU [9], which any European country should be encouraged to adopt.

The economic backgrounds of the participating countries were also very heterogeneous, four of 11 countries had GDP per capita under 10,000 USD and nine of 11 countries under 20,000 USD. Moldova with lowest GDP per capita maintained better standards of PKU screening and management as compared to some other countries with relatively 2 to 3 -times higher GDP per capita. Financial situation seemed not to be the most important factor of the standard of the PKU screening and management, which we believe was an important and encouraging finding of the study.

The newly published proceedings of the PKU scientific review conference are providing one of the most comprehensive and up-to-date understandings of PKU available [8]. The preparation and publication of the proceedings perfectly coincides with fifty years anniversary of the Guthrie's discovery and implementation of first newborn screening programs for PKU. In the 1970s the screening for PKU was mandatory in nearly all industrialized European countries [26]. PKU screening is a prerequisite for an early implementation of the phenylalaninerestricted diet, preventing and eliminating the severe neurological impairment typical for untreated PKU patients $[5,27]$. Nevertheless, the people from many developing countries throughout the world are not taking a part in any of advances in the field of PKU of the last 50 years [28]. The report from year 2004 that outlined the status of neonatal screening for PKU has included 7 countries from southeastern Europe [29]. Moldova had no screening in year 2004 and Montenegro was a part of Serbian screening program $[18,29]$. The breakup of former Yugoslavia after inter-ethnic wars resulted in newly established countries with limited resources. Consequently, the screening statistics is not significantly better after 10 years. Bosnia, Bulgaria, Croatia, Serbia and Slovenia continued or improved the screening program while other countries in the region with the exception of Romania did not implement the screening [30].

Sporadic reports from certain developing countries (e.g. Tunisia, Lebanon, Iran) without newborn PKU screening show PKU to be one of the most common preventable causes of mental retardation [28, 31-33]. A significant group of mentally impaired patients is expected in Balkan Peninsula because of the late or absent introduction of the screening [30,34]. Additionally the families miss the opportunity for genetic counseling without a proper diagnosis and maternal PKU is not prevented. Furthermore, some other studies are showing 
that the introduction of newborn screening in developing countries would clearly be a cost-effective decision $[28,35]$.

We firmly believe that implementation of basic standards of PKU management to the developing parts of the world should be among priorities when identifying future medical and research needs, while these efforts should be supported by relevant professional forums, patients' organizations and also industry $[9,28]$. One such emerging initiative is that by the E.S.PKU, which very recently proposed the need for recommendations for a minimum standard of care for PKU, also arguing for equal access to screening, treatment and monitoring throughout Europe [9].

\section{Conclusions}

This was the first study to assess the PKU screening and management characteristics in the 11 countries from southeastern Europe, identifying several important challenges. Neonatal PKU screening should be introduced throughout the region. Furthermore, PKU management was falling behind internationally established standardsof-care in many aspects. We firmly believe that implementation of basic standards of PKU management to the developing parts of the world should be among future priorities.

\section{Additional file}

Additional file 1: Questionnaire on the PKU management and the newborn screening in the region of the South-Eastern Europe.

\section{Abbreviations}

BH4: Tetrahydrobiopterin; E.S.PKU: European society for phenylketonuria and allied disorders; GDP: Gross domestic product; HPA: Hyperphenylalaninaemia; mio: Milion; PAH: Phenylalanine hydroxylase; Phe: Phenylalanine; PKU: Phenylketonuria; Tyr: Tyrosine.

\section{Competing interests}

The authors declare that they have no competing interests.

\section{Authors' contributions}

Study was designed by MZT, UG and TB, all of them also performed data analysis and wrote the manuscript. All authors contributed to data collection and critically reviewed and approved the manuscript.

\section{Acknowledgments}

The study was supported in part by the Slovenian National Research Agency grants J3-2412, J3-9663 and P3-0343.

\footnotetext{
Author details

'University Children's Hospital Ljubljana, UMC Ljubljana, Ljubljana, Slovenia. ${ }^{2}$ University Children's Hospital Skopje, Skopje, Macedonia. ${ }^{3}$ Clinical Hospital for Children "Sfanta Maria", lasi, Romania. ${ }^{4}$ Department of Pediatrics, University Hospital Center Zagreb, Zagreb, Croatia. ${ }^{5}$ Mother and Child Health Care Institute of Serbia, Belgrade, Serbia. ${ }^{6}$ University Hospital Center "Mother Teresa", Tirana, Albania. " National Genetics Laboratory, Sofia, Bulgaria. ${ }^{8}$ University Pediatric Hospital Sofia, Sofia, Bulgaria. ${ }^{9}$ Pediatric Clinic, University Clinical Center Pristina, Pristina, Kosovo. ${ }^{10}$ University Clinical Center Sarajevo, Sarajevo, Bosnia and Herzegovina. "'Clinical Hospital of Targu Mures, Targu Mures, Romania. ${ }^{12}$ Clinica Hospital for Children "Luis Turcanu", Timisoara,
}

Romania. ${ }^{13}$ Mother and Child Health Care Institute "Alfred Rusescu", Bucharest, Romania. ${ }^{14} \mathrm{Clinical}$ Hospital for Children "Iuliu Hateganu", Cluj-Napoca, Romania. ${ }^{15}$ Institute for Sick Children, Clinical Center of Montenegro, Podgorica, Montenegro. ${ }^{16}$ Institute of Molecular Genetics and Genetic Engineering, University of Belgrade, Belgrade, Serbia. ${ }^{17}$ Children Hospital Banja Luka, Banja Luka, Republic of Srpska, Bosnia and Herzegovina. ${ }^{18}$ Department of Medical Sciences, Academy of Sciences and Arts of Bosnia and Herzegovina, Sarajevo, Bosnia and Herzegovina. ${ }^{19}$ Department of Pediatrics, University Clinical Center Tuzla, Tuzla, Bosnia and Herzegovina. ${ }^{20}$ Institute of Mother and Child, Centre of Reproductive Health and Medical Genetics, Chisinau, Moldova. ${ }^{21}$ School of Medicine, University of Zagreb, Zagreb, Croatia. ${ }^{22}$ Department of Pediatrics, Faculty of Medicine, University of Ljubljana, Ljubljana, Slovenia.

Received: 15 December 2014 Accepted: 12 May 2015

Published online: 30 May 2015

\section{References}

1. Scriver $C R$, Kaufman $S$. Hyperphenylalaninemia: phenylalanine hydroxylase deficiency. In: Scriver CR, Beaudet AL, Sly WS, Valle D, Childs B, Vogelstein B, editors. The metabolic and molecular basis of inherited disease. New York: Mc-Graw Hill; 2001. p. 1667-724.

2. Hardelid P, Cortina-Borja M, Munro A, Jones H, Cleary M, Champion MP, et al. The birth prevalence of PKU in populations of European, South Asian and sub-Saharan African ancestry living in South East England. Ann Hum Genet. 2008;72:65-71.

3. Blau N, van Spronsen FJ, Levy HL. Phenylketonuria. Lancet. 2010;376:1417-27.

4. Blau N, MacDonald A, van Spronsen FJ. There is no doubt that the early identification of PKU and prompt and continuous intervention prevents mental retardation in most patients. Mol Genet Metab. 2011;104:S1.

5. Berry SA, Brown C, Grant M, Greene CL, Jurecki E, Koch J, et al. Newborn screening 50 years later: access issues faced by adults with PKU. Genet Med. 2013;15:591-9.

6. US Preventive Services Task Force. Screening for phenylketonuria (PKU): US Preventive Services Task Force Reaffirmation recommendation. Ann Fam Med. 2008;6:166.

7. National Institutes of Health Consensus Development Conference Statement. Phenylketonuria: screening and management. Pediatrics. 2001;108:972-82

8. Camp KM, Parisi MA, Acosta PB, Berry GT, Bilder DA, Blau N, et al. Phenylketonuria Scientific Review Conference: state of the science and future research needs. Mol Genet Metab. 2014;112:87-122.

9. Hagedorn TS, van Berkel P, Hammerschmidt G, Lhotáková M, Saludes RP. Requirements for a minimum standard of care for phenylketonuria: the patients' perspective. Orphanet J Rare Dis. 2013;8:191.

10. Schweitzer-Krantz S, Burgard P. Survey of national guidelines for the treatment of phenylketonuria. Eur J Pediatr. 2000;159:70-3.

11. van Spronsen FJ, Ahring KK, Gizewska M. PKU-what is daily practice in various centres in Europe? Data from a questionnaire by the scientific advisory committee of the European Society of Phenylketonuria and Allied Disorders. J Inherit Metab Dis. 2009;32:58-64.

12. Ahring K, Bélanger-Quintana A, Dokoupil K, Gokmen Ozel H, Lammardo AM, MacDonald $A$, et al. Dietary management practices in phenylketonuria across European centres. Clin Nutr. 2009;28:231-6.

13. Blau N, Bélanger-Quintana A, Demirkol M, Feillet F, Giovannini M, MacDonald A, et al. Management of phenylketonuria in Europe: survey results from 19 countries. Mol Genet Metab. 2010;99:109-15.

14. Ahring K, Bélanger-Quintana A, Dokoupil K, Gokmen-Ozel H, Lammardo AM, MacDonald A, et al. Blood phenylalanine control in phenylketonuria: a survey of 10 European centres. Eur J Clin Nutr. 2011;65:275-8.

15. Zschocke J, Preusse A, Sarnavka V, Fumic K, Mardesic D, Hoffmann GF, et al. The molecular basis of phenylalanine hydroxylase deficiency in Croatia. Hum Mut. 2003;21:399.

16. Jeran N, Havas D, Ivanovic V, Rudan P. Genetic diversity of 15 STR loci in a population of Montenegro. Coll Antropol. 2007;31:847-52.

17. Kremensky I, Jordanova A, Michaylova E, Todorova A, Ivanova M, Petkova R et al. Laboratory diagnosis of inherited disorders and congenital anomalies in Bulgaria. Balkan J Med Genet. 2000;3:13-22.

18. Stojiljkovic M, Jovanovic J, Djordjevic M, Grkovic S, Cvorkov Drazic M, Petrucev B, et al. Molecular and phenotypic characteristics of patients with phenylketonuria in Serbia and Montenegro. Clin Genet. 2006;70:151-5. 
19. Baric I, Mardesic D, Gjuric G, Sarnavka V, Gobel-Schreiner B, Lichter-Konecki $\mathrm{U}$, et al. Haplotype distribution and nutations at the PAH locus in Croatia. Hum Genet. 1992;90:155-7.

20. Groselj U, Tansek MZ, Kovac J, Hovnik T, Podkrajsek KT, Battelino T. Five novel mutations and two large deletions in a population analysis of the phenylalanine hydroxylase gene. Mol Genet Metab. 2012;106:142-8.

21. Popescu T, Blazkova M, Kozak L, Jebeleanu G, Popescu A. Mutation spectrum and phenylalanine hydroxylase RFLPNNTR background in 44 Romanian phenylketonuric alleles. Hum Mut. 1998;12:314-9.

22. Groselj U, Tansek MZ, Podkrajsek KT, Battelino T. Genetic and clinical characteristics of patients with phenylketonuria in Slovenia. Zdrav Vestn. 2013:82:767-77.

23. Karacic I, Meili D, Sarnavka V, Heintz C, Thöny B, Ramadza DP, et al. Genotypepredicted tetrahydrobiopterin (BH4)-responsiveness and molecular genetics in Croatian patients with phenylalanine hydroxylase (PAH) deficiency. Mol Genet Metab. 2009;97:165-71.

24. Djordjevic M, Klaassen K, Sarajlija A, Tosic N, Zukic B, Kecman B, et al. Molecular genetics and genotype-based estimation of BH4-Responsiveness in Serbian PKU patients: spotlight on phenotypic implications of p.L48S. JIMD Rep. 2013;9:49-58.

25. Tansek MZ. Phenylketonuria - a story about a successful therapy of an inborn error of metabolism. Slov Pediatr. 2003;10:225-35.

26. Brosco JP, Paul DB. The political history of PKU: reflections on 50 years of newborn screening. Pediatrics. 2013;132:987-9.

27. Battelino T, Krzisnik C, Pavlin K. Early detection and follow up of the children with phenylketonuria in Slovenia. Zdrav Vestn. 1994;63 Suppl 1:25-8

28. Groselj U, Zerjav Tansek M, Battelino T. Fifty years of phenylketonuria newborn screening - a great success for many, but what about the rest? Mol Genet Metab. 2014;113:11-3.

29. Loeber JG. Neonatal screening in Europe: the situation in 2004. J Inherit Metab Dis. 2007:30:430-8.

30. Groselj U, Zerjav Tansek M, Smon A, Angelkova N, Anton D, Baric I, et al. Newborn screening in Southeastern Europe. Mol Genet Metab. 2014;113:45-8

31. Khemir S, El Asmi M, Sanhaji H, Feki M, Jemaa R, Tebib N, et al. Phenylketonuria is still a major cause of mental retardation in Tunisia despite the possibility of treatment. Clin Neurol Neurosurg. 2011;113:727-30.

32. Karam PE, Daher RT, Moller LB, Mikati MA. Experience with hyperphenylalaninemia in a developing country: unusual clinical manifestations and a novel gene mutation. J Child Neurol. 2011;26:142-6.

33. Ghiasvand NM, Aledavood A, Ghiasvand R, Seyedin Borojeny F, Aledavood $A R$, Seyed $S$, et al. Prevalence of classical phenylketonuria in mentally retarded individuals in Iran. J Inherit Metab Dis. 2009;32 Suppl 1:283-7.

34. Koch R, Moseley K, Ning J, Romstad A, Guldberg P, Guttler F. Long-term beneficial effects of the phenylalanine-restricted diet in late-diagnosed individuals with phenylketonuria. Mol Genet Metab. 1999:67:148-55.

35. Sladkevicius E, Pollitt RJ, Mgadmi A, Guest JF. Cost effectiveness of establishing a neonatal screening programme for phenylketonuria in Libya. Appl Health Econ Health Policy. 2010;8:407-20

\section{Submit your next manuscript to BioMed Central and take full advantage of:}

- Convenient online submission

- Thorough peer review

- No space constraints or color figure charges

- Immediate publication on acceptance

- Inclusion in PubMed, CAS, Scopus and Google Scholar

- Research which is freely available for redistribution 